\title{
Ética e moral epicurista em Così parlò Bellavista, de Luciano de Crescenzo
}

\author{
Epicurean ethics and moral in Così parlò Bellavista, \\ by Luciano de Crescenzo
}

Matheus Santos Bueno ${ }^{1}$

1 Mestrando do Programa de Pós-Graduação em Letras da Universidade Estadual Paulista "Júlio de Mesquita Filho", Brasil. E-mail: matheus.s.bueno@hotmail.com

RESUMO: Este artigo analisa, aproximando as áreas da Literatura e da Filosofia, a Moral e a Ética sob a perspectiva do filósofo grego Epicuro, na obra italiana Cosi parlò Bellavista: Napoli, amore e libertà (Assim falou Bellavista: Nápoles, amor e liberdade), de Luciano de Crescenzo, publicada em 1977. Apesar das ideias de Epicuro terem sido concebidas há séculos do personagem professor de filosofia Gennaro Bellavista, este acredita que os napolitanos se comportam conforme os ensinamentos do mestre grego: pela via do prazer e pela negação das dores físicas e das atribulações mentais. Ainda que a análise de Bellavista seja pautada em Epicuro, o professor acrescenta suas próprias reflexões sobre a vida em Nápoles, contextualizando a filosofia epicurista para esse povo. A partir deste contexto, busca-se analisar também, com base na antinomia utilizada no pensamento filosófico apolíneo-dionisíaco, por trechos do romance e pela análise de uma anedota, intitulada "Geraldinho, o kamikaze", presente no livro estudado, como os napolitanos podem ser observados por esse viés. Observa-se que os napolitanos, pensados pelo professor Bellavista, seguem um comportamento epicurista-napolitano: ética e moral são pautadas nas características do dionisíaco, isto é, preferência pela desordem, desprezo pelas leis e desfrute dos prazeres primários, segundo a classificação dos prazeres de Epicuro.

Palavras-chave: Epicuro; Ética; Moral.

ABSTRACT: This article analyzes, approximating the areas of Literature and Philosophy, Moral and Ethics from the perspective of the Greek philosopher Epicurus, in the Italian work Cosi parlò Bellavista: Napoli, amore e libertà (Thus spake Bellavista: Naples, love and liberty), published in 1977. Although the ideas of Epicurus were conceived centuries ago of the character of philosophy professor Gennaro Bellavista, he believes that the Neapolitans behave according to the teachings of the Greek master: priming the primary pleasures and the denial of physical pain and mental tribulations. Despite the analysis of Bellavista is based on Epicurus, the professor adds his own reflections on life in Naples, contextualizing the epicurean philosophy for this people. In this context, it is also sought to analyze, based on the antinomy used in philosophical studies Apollonian-Dionysian, by excerpts from the novel and analysis of an anecdote, entitled "Gennarino, the Kamikaze", present in the studied book, how Neapolitans can be observed by this perspective. It is observed that the Neapolitans, thought by Professor Bellavista, follow an Epicurean-Neapolitan behavior: ethics and moral are based on the characteristics of the Dionysian, this is, preference for disorder, contempt for laws and enjoyment of primary pleasures, according to the classification of pleasures of Epicurus.

Keywords: Epicurus; Ethics; Moral.

Por representarem e refletirem o pensamento humano, a Literatura e a Filosofia têm convergências entre si. Escritores de ficção e de Filosofia se interessam em explorar as implicações de como o homem vive 
e sente o mundo. Segundo Pedro Emanuel Quintino de Souza (2007, p. 23), ambos escritores tentam explicitar as experiências humanas, torná-las mais transparentes ou ainda pensar situações incompreensíveis para explorá-las. Contudo, mesmo que os escritores de ficção tentem, assim como os filósofos, desvendar os mistérios da existência humana, o fazem de maneiras distintas. O filósofo precisa ordenar a linguagem, tornála precisa e clara, sem ambiguidades. O escritor de ficção, no entanto, pode ser ambíguo, atribuindo à sua escrita diversas significações.

Ademais, na Literatura ficcional, o autor pode deixar explícita ou implícita as teorias que guiam sua obra, como, por exemplo, no comportamento ou no modo de pensar dos personagens. Além disso, Souza questiona:

Qualquer obra literária, independentemente da sua história ou teor descritivo, tem a capacidade de incorporar juízos de valor, não só pelo que é dito, mas pelos temas que o escritor escolhe inscrever a sua obra. Não bastará, por exemplo, que uma história seja sobre relações interpessoais para que se teçam considerações sobre moral, valores e comportamentos? (SOUZA, 2007, p. 24)

Vê-se, a partir dos apontamentos de Souza, que muito pode estar subjacente no texto literário, não só descrições e temas, juízos de valor, relações interpessoais, mas também considerações sobre moral, valores e comportamentos.

Assim ocorre com a obra estudada aqui, principalmente porque evidencia o pensamento filosófico epicurista ao ser destacado como os personagens são imbuídos de valores e comportamentos abertamente discutidos pelo personagem Bellavista ao longo do romance. É possível refletir, então, na ficção de De Crescenzo, os valores morais e éticos que a configuram, destacando, dessa maneira, a relação muitas vezes intrínseca entre Literatura e Filosofia.

No prefácio da obra não ficcional de De Crescenzo, na qual reúne os principais filósofos gregos, explicando sobre a vida e o pensamento deles, intitulada História da Filosofia grega: os pré-socráticos (2012a), o autor explicita a sua fascinação pela Filosofia e o porquê a acha importante. Para ele, essa área do conhecimento nos auxilia a descobrir nossos comportamentos e a identificar nossa posição no mundo, além de ser: "uma prática proveitosa do ser humano para enfrentar os problemas miúdos do dia-a-dia[...]” (2012a, p.9). Contudo, há um obstáculo, segundo o autor, que se refere a como alguns estudiosos tornaram a linguagem filosófica difícil e isso resultou no desinteresse da maioria das pessoas. De Crescenzo busca, em suas obras, sejam elas romanescas ou ensaísticas, tornar a Filosofia interessante e palatável aos seus leitores. A inserção de pequenas anedotas opera, tanto nos romances quanto nos ensaios, como demonstrações práticas, divertidas ou lúdicas das crenças filosóficas aplicadas no cotidiano napolitano e mescladas à vida do autor. Nesse sentido, sua faceta pedagógica é revelada por se preocupar em semear o conhecimento filosófico de forma que o leitor consiga se identificar com as histórias narradas e, ao mesmo tempo, absorver as reflexões filosóficas. Ele afirma:

Alguns filósofos em particular, depois de se quebrar o gelo com eles, acabarão aparecendo tão familiares que você vai achá-los até parecidos com as pessoas do seu círculo de amizades. Aristotélicos, platônicos, sofistas, céticos, epicuristas, cínicos, cirenaicos, poderiam tornar-se referências muito eficazes, quando usadas com acerto, do que os signos do Zodíaco para identificar o estilo mental de uma pessoa. (DE CRESCENZO, 2012a, p. 11)

Luciano De Crescenzo demonstra seu interesse genuíno acerca do pensamento filosófico, como 
visto na citação, ao afirmar que a Filosofia pode atuar praticamente em nossas vidas.

Sobre De Crescenzo, pode-se afirmar que começou a carreira como escritor depois dos 40 anos de idade. Antes de ser escritor, formou-se como engenheiro e trabalhou durante muitos anos na IBM italiana, empresa de computadores, alcançando o cargo de diretor. Após o sucesso de vendas de seu primeiro romance, Cosi parlò Bellavista, foi convidado pela editora Mondadori a se tornar escritor em tempo integral. Desde então, dedica-se a escrever romances que tocam a Mitologia, tais como em Elena, Elena, meu amor (1991), no qual reconta a tragédia de Tróia pelos olhos de um garoto de quatorze anos, ou em Ulisse era un fico (2010), no qual reconta a trajetória do herói Ulisses, valendo-se de passagens autobiográficas.

Além de obras com temas baseados na Mitologia, também escreve ensaios sobre diversos temas com teor filosófico. A obra História da Filosofia Grega (2012), na qual resgata os principais filósofos gregos e suas ideias, foi elogiada pela crítica especializada por conta da didática e da precisão histórica contidas nela. Como a obra foi bem recebida, o autor lançou outros volumes: História da Filosofia Medieval (2002) e História da Filosofia Moderna (2004).

O conjunto da obra do autor é marcado por um hibridismo de gêneros. Tanto os romances, quanto os ensaios filosóficos são caracterizados pela inserção de outros gêneros literários. Na obra ensaística Ordem e desordem (1996), há reflexões sobre o Tempo, a Ética, a Moral, o Bem, o Mal e sobre a dicotomia entre o apolíneo e o dionisíaco, sempre configuradas pelo bom humor e dispondo de passagens autobiográficas.

Em Cosi parlò Bellavista, o próprio autor se questiona, na introdução do romance, se a obra pode ser considerada um romance ou um ensaio. Nela, reflete sobre questões filosóficas e experiências que afirma serem pessoais. Segundo De Crescenzo:

Ensaio ou narrativa? Digamos que os capítulos ímpares aspiram ao ensaio, ainda que tenham sido escritos em forma puramente discursiva, e os capítulos pares à narrativa, não sendo outra coisa que simples anedotas napolitanas, algumas vividas verdadeiramente em primeira pessoa e outras recontadas pela crônica. ${ }^{1}$ (DE CRESCENZO, 1977, p. 7, tradução minha).

Sendo assim, o romance é dividido em duas narrativas. A narrativa principal é composta pelas discussões sobre diversos temas entre os amigos Vittorio, Luigino, Salvatore, Saverio, a voz ficcional do próprio De Crescenzo, chamado no romance pelos seus colegas de "engenheiro" e pelo personagem principal Gennaro Bellavista. As narrativas secundárias são "simples anedotas", ou seja, são narrativas curtas e divertidas que não fazem parte da narrativa principal, mas explicitam uma ideia exposta nela. O autor afirma na introdução do romance:

O livro, em resumo, pode ser lido unicamente nos seus capítulos pares ou, segundo a vontade e disposição do leitor, também nos capítulos ímpares, nos quais é posto em prática, como em um velho texto de geometria, teoremas enunciados e, logo em seguida, os exemplos demonstrativos, de modo que as anedotas napolitanas, reportadas nos capítulos pares, se tornam a demonstração de algumas teorias filosóficas expressas pelo professor em seus diálogos sobre o amor e a liberdade. ${ }^{2}$ (DE CRESCENZO,

\footnotetext{
${ }_{1}$ Saggistica o narrativa? Diranno che i capitoli dispari aspirano alla prima qualifica, malgrado siano stati scritti in forma puramente discorsiva, ed i capitoli pari alla narrativa, non essendo altro che semplici fattarielli napoletani, alcuni vissuti veramente in prima persona ed altri raccolti dalla cronaca. (DE CRESCENZO, 1977, p. 7)

2 II libro insomma, pur potendo essere letto soltanto nei suoi capitoli pari o, a secondo dell'impegno messo a disposizione dal lettore, anche in quelli dispari, si presenta in pratica come un vecchio testo di geometria dove ai teoremi enunciati seguano gli esempi dimostrativi, in modo che gli aneddoti napoletani riportati nei capitoli pari diventino $i$ come volevasi dimostrare di certe teorie filosofiche espresse dal professore nei suoi dialoghi sull'amore e sulla libertà. (DE CRESCENZO, 1977, p. 7)
} 
1977, p. 7, tradução minha).

Dividida entre as anedotas e os diálogos dos amigos, a obra toca a cultura popular napolitana, guiada pela interpretação filosófica do professor. Apesar de De Crescenzo deixar claro que as teorias filosóficas de Bellavista são pautadas em Epicuro, o personagem as emprega de sua perspectiva ao analisar o povo napolitano em seu próprio contexto. O autor, então, sendo um escritor de ficção, tem a liberdade em adaptar a percepção epicurista de forma criativa e que tenha um novo sentido em sua obra ficcional. Nela, entre outros temas, é explorada, filosoficamente, as condutas morais e éticas dos personagens napolitanos.

Segundo o Dicionário de Filosofia, Moral é definida como: “1. O mesmo que Ética. 2. Objeto da ética, conduta dirigida ou disciplinada por normas, conjunto dos mores" (2007, p. 682). Ética é definida como: "ciência para o qual a conduta dos homens deve ser orientada e dos meios para atingir tal fim, deduzindo tanto o fim quanto os meios da natureza do homem.” (2007, p. 390)

A Filosofia é uma das áreas do conhecimento que Luciano De Crescenzo mais se dedicou a escrever, além de, como afirmado anteriormente, se basear nela para desenvolver seus romances. Na obra Cosi parlò Bellavista, há menções a filósofos importantes. Um deles é Friedrich Nietzsche (1844-1900), referenciado no próprio título do livro: Cosi parlò Bellavista (Assim falou Bellavista, em português) pois parodia o título da obra de Nietzsche Assim falou Zaratustra. Nesta obra, surge, pela primeira vez, a reflexão sobre o superhomem, uma das ideias mais conhecidas do filósofo alemão, pelo famoso personagem Zaratustra, também conhecido como Zoroastes (na versão grega de seu nome), profeta e poeta nascido na Pérsia. Acredita-se que, em meados do século VII a.C., foi o fundador do "Masdeísmo" ou "Zoroastrismo", a primeira religião monoteísta ética da História.

No trecho do capítulo vinte e cinco, intitulado "La rosa dei 16 mestiere" (A rosa das 16 vocações), do romance estudado aqui, Bellavista expõe as diferenças de seu ponto de vista em relação àquele de Zaratustra. O professor, tendo nascido em Nápoles, só pode tender ao amor, segundo as categorias que ele mesmo elaborou e que serão discutidas na próxima sessão, a saber: amor, liberdade, poder e ódio. Nietzsche, todavia, é descrito como difícil de ser classificado: "Meus amigos, esse Nietzsche é um senhor realmente difícil de classificar: que foi um grande poeta e ao mesmo tempo um homem de ódio, não há dúvidas...’’ (De Crescenzo, 1977, p. 128, tradução minha). Depois dessa afirmação, a completa refletindo que Zaratustra, no entanto, talvez se encaixe em todas suas categorias. Desta forma, ainda que o título da obra de De Crescenzo faça referência à obra de Nietzsche, a relação que se estabelece é apenas paródica. Bellavista é diferente do personagem do filósofo alemão no que se refere às crenças teóricas e filosóficas. A correlação que se pode estabelecer entre ambos é a de que Bellavista explicita aos seus colegas sua visão de mundo e adequa sua teoria sobre a vivência dos homens ao rigor da Filosofia, assim como Zaratustra o faz.

Outro filósofo citado, quando é explicado que Nápoles é ocupada por pessoas que tendem ao amor, é Mo tse ti ou Mozi (470 a.C, -391 a.C.), filósofo chinês que criou a escola do "Moísmo", pertencente também à escola do Taoísmo. O chinês tinha como ideia central o amor universal.

No trecho do capítulo sete de Cosi parlò Bellavista, intitulado "La teoria dell'amore e della libertă" (A teoria do amor e da liberdade), Saverio pergunta à Bellavista quais eram os ensinamentos de Mozi, ao passo que o professor responde: "Dizia que era necessário amar todo o universo. Que se deve amar os pais dos outros da mesma maneira que se ama os próprios pais. Em suma, pregava o amor universal e dizia que o mal do

\footnotetext{
${ }^{3}$ Amici miei, questo Nietzsche qua è un signore veramente difficile da classificare che sia stato un grande poeta e nello stesso tempo un uomo d'odio non ci sono dubbi...? (DE CRESCENZO, 1977, p. 128)
} 
mundo era a "descriminação" (DE CRESCENZO, 1977, p. 57, tradução minha).

Para Mozi, o homem deve agir de modo que suas ações reflitam compaixão e interesse genuínos pelas outras pessoas em qualquer contexto, seja doméstico, de amizade ou de trabalho. Segundo Russel Kirkland:

Mozi é muito conhecido por sua insistência em que todas as pessoas são igualmente merecedoras em receberem benefícios materiais e serem protegidas de danos físicos. Nesse sentido, ele era um idealista: como Confúcio, ele acreditava que a sociedade deveria ser guiada pelos sábios e pelos virtuosos. Mas a definição de Mozi para sabedoria e virtude revelou uma mentalidade muito mais prática, como também uma intensa dedicação em alcançar uma sociedade na qual as pessoas trabalhassem para salvarem-se entre si de danos físicos e da privação. ${ }^{5}$ (KIRKLAND, s.d., p. 1)

Vê-se no filósofo chinês a ideia de igualdade entre as pessoas e a preocupação em manter-se distante de dores físicas, tal qual aparece em Epicuro.

Epicuro de Samos (341 a.C.-270 a.C.) foi filósofo grego do período helenístico que discutiu sobre Moral e Ética partindo do pressuposto de que se deve evitar as dores físicas e o desgaste mental. O filósofo nasceu na ilha grega de Samos, daí o nome do local estar associado ao seu primeiro nome e ser conhecido como Epicuro de Samos. Ainda jovem, mudou-se para Atenas para completar seus estudos e, depois de morar em outros locais, voltou a esta mesma cidade para fundar "O jardim de Epicuro", escola onde difundiu seus pensamentos e na qual conseguiu mais seguidores. Segundo De Crescenzo: "Por ser uma escola baseada na amizade, a entrada só podia ser franca. O jardim era frequentado por pessoas de todos os níveis sociais: adultos, jovens, metecos e escravos, figurões atenienses e lindas heteras" (2012b, p. 175). Seu pensamento foi muito difundido e inúmeros centros epicuristas surgiram na Jônia, no Egito e, a partir do século I, também em Roma, onde Lucrécio foi seu grande divulgador.

José Américo Motta Pessanha, na introdução sobre Epicuro, da série Os pensadores, afirma: "Os alunos não têm em Epicuro um mestre no estilo tradicional: na verdade, formam um grupo de amigos que filosofam juntos. Epicuro exerce influência, não só pelo ensino direto como pela extraordinária personalidade" (1985, p. 8).

De Crescenzo afirma também sobre a personalidade do filósofo, em História da Filosofia grega: de Sócrates aos neoplatônicos: "Para Epicuro, a amizade era algo a ser transmitido de um homem para outro, quase como um contágio, tipo uma corrente de Santo Antônio" (DE CRESCENZO, 2012b, p. 178). Percebe-se que o modo do filósofo em transmitir seus ensinamentos, por intermédio da amizade e do diálogo fraternal, embasa também, além dos princípios filosóficos, a maneira com a qual o personagem Bellavista é configurado no romance, isto é, expondo suas teorias mediante diálogos fraternais entre amigos, assim como

${ }^{4}$ Diceva che bisogna amare tutto l'universo. Che uno deve amare i genitori degli altri nella stessa maniera con cui ama i propri genitori. Insomma predivaca l'amore universale e diceva que il male del mondo era la "descriminazione".(DE CRESCENZO, 1977, p. 57)

${ }^{5}$ Mozi is best known for his insistence that all people are equally deserving of receiving material benefit and being protected from physical harm. In one sense, he was an idealist: like Confucius, he believed that society should be led by the wise and the virtuous. But Mozi's definitions of wisdom and virtue revealed a much more practical mentality, as well as an intense dedication to achieving a society in which people worked to save each other from physical harm and deprivation. Trecho retirado do texto "The book of Mozi (Mo Tzu)" do especialista em religiões e filosofia chinesas, professor emérito Russel Kirkland da University of Georgia, Estados Unidos. Disponível no site da Universidade em: <<// https://faculty.franklin.uga.edu/sites/faculty.franklin.uga.edu.kirkland/files/MOTZU.pdf//>>, tradução minha. Acesso em 13 de março de 2019. 
Epicuro o fazia.

Sendo o mestre grego o principal filósofo que respalda as teorias de Bellavista, será analisada a perspectiva epicurista de ética e moral dos napolitanos neste artigo. Para tanto, serão utilizados trechos da narrativa principal e uma anedota presente no romance, intitulada "Genarinno, o'kamikaze" (traduzida aqui como "Geraldinho, o kamikaze”), anexada na íntegra no fim deste artigo. Além disso, também será explorada, na seção seguinte, a antinomia apolíneo-dionisíaco, aqui utilizada para compreender as categorias de amor, liberdade, poder e ódio que Bellavista acredita existir e as quais usa para classificar pessoas e sociedades.

\section{Epicuro, ética e moral napolitanas e a antinomia apolíneo-dionisíaco}

As ideias de Epicuro relacionadas à divisão dos prazeres e à busca pela felicidade foi escrita para um de seus discípulos mais fiéis: Meneceu, em Carta sobre a felicidade. Nessa carta, o filósofo propõe a divisão dos prazeres e expõe os caminhos necessários para se viver uma vida plena.

Esses preceitos são explorados por Bellavista em diversos capítulos do romance. Em "Epicuro", capítulo onze, o professor napolitano apresenta aos seus colegas quem foi o filósofo e suas principais ideias. No trecho a seguir, ele explica a Saverio a divisão dos prazeres:

"Então", continua Bellavista "Epicuro dizia que existiam três tipos de prazeres: os prazeres primários que são naturais e necessários, os prazeres secundários que são naturais mas não necessários e os prazeres vãos que não são nem naturais nem necessários."

"Não entendi, professor, mas de quais prazeres fala?"

"Um pouco de atenção e me explico melhor. Então, os prazeres primários são aqueles naturais e necessários, como comer, beber, dormir e a amizade."

"Comer, beber, dormir, a amizade e basta? Pergunta Saverio. "Professor, está seguro de que não esqueceu nada de muito importante?"

"Não, Savè, para Epicuro o sexo era um prazer secundário natural, mas não necessário." 6 (DE CRESCENZO, 1977, p. 88, tradução minha)

O professor continua explicando que, além dos prazeres primários e secundários, existem também os prazeres terciários que não são nem naturais e nem necessários. O exemplo que ele usa de prazer terciário é o poder, tido como um sentimento vão. O desejo de poder e a vontade de comandar fogem do equilíbrio necessário para se atingir a felicidade, segundo a perspectiva epicurista.

Assim como exposto pelo napolitano, Epicuro pensou os prazeres divididos em categorias. Nas palavras de Epicuro:

Consideremos também que, dentre os desejos, há os que são naturais, há uns que são necessários e

\footnotetext{
6"Dunque," continua Bellavista "Epicuro diceva che esistono tre tipi di piaceri: i piaceri primari che sono naturali e necessari, i piaceri secondari che sono naturali ma non necessari ed i piaceri vani che non sono nè naturali nè necessari."
}

"Non ho capito professò, ma di quali piaceri parlate?"

"Un poco di attenzione e mi spiego meglio. Dunque i piaceri primari, quelli cioè naturali e necessari, sono il mangiare, il bere, il dormire e l'amicizia."

"Mangiare, bere, dormire, l'amicizia e basta? chiede Saverio. "Professò, ma siete sicuro che non vi siete dimenticato qualcosa di veramente importante?"

“No Savè, per Epicuro il sesso era un piacere secondario, ovvero naturale ma non necessario." (DE CRESCENZO, 1977, p. 88) 
outros, apenas naturais; dentre os necessários, há alguns que são fundamentais para a felicidade, outros, para o bem-estar corporal, outros, ainda, para a própria vida. E o conhecimento seguro dos desejos leva a direcionar toda recusa para a saúde do corpo e para a serenidade do espírito, visto que esta é a finalidade da vida feliz: em razão desse fim praticamos todas as nossas ações, para nos afastarmos da dor e do medo. (EPICURO, 2002, p. 35)

O filósofo grego alegava que para o homem atingir a felicidade era necessário que ele se libertasse das dores físicas e mentais. José Américo Motta Pessanha afirma (1985, p. 9): "Para Epicuro, o prazer que deve nortear a conduta humana — o prazer com dimensão ética e não apenas natural — é o 'prazer do repouso', constituído pela ataraxia (ausência de perturbação) e pela aponia (ausência de dor)." A ausência de dores físicas e das perturbações mentais, então, garantiria a felicidade do homem. Para que isso se concretize, são necessárias a reflexão e a avaliação do que é estritamente indispensável para se viver.

Epicuro pregava que o caminho para a aponia e para a ataraxia era pela via dos prazeres, mas que não devem ser confundidas com o Hedonismo: busca irrefreada pelos prazeres carnais e sensuais. Na teoria epicurista, os prazeres gerados pela alimentação e pelo sexo devem ser contidos. O filósofo afirma:

[...] bebidas nem banquetes contínuos, nem a posse de mulheres e rapazes, nem o sabor dos peixes ou das outras iguarias de uma mesa farta tornam doce uma vida, mas um exame cuidadoso que investigue as causas de toda escolha e de toda rejeição e que removas as opiniões falsas em virtude das quais uma imensa perturbação toma conta dos espíritos. (EPICURO, p. 45, 2002)

Para ele, deve-se viver os prazeres primários apenas para suprir as necessidades humanas, sem que elas se tornem vícios e possam causar perturbações físicas e mentais. Neste sentido, apenas o necessário para a sobrevivência é eticamente aceitável.

O personagem Bellavista sustenta que os napolitanos seguem os prazeres classificados por Epicuro, pois um de seus seguidores, Filodemo de Gádara, teria ensinado o povo da região de Nápoles sobre a divisão dos prazeres e o desprezo pelo poder. Ele afirma:

Porque um dos principais seguidores de Epicuro foi um certo Filodemo de Gádara, que viveu no século I depois de Cristo. Filodemo se mudou para Nápoles, em Herculano para ser específico, e aqui fundou uma importantíssima escola epicurista no modelo "Jardim de Atenas". Nesta escola, Filodemo ensinava o povo napolitano a classificação dos prazeres e o desprezo pelo poder. ${ }^{7}$ (DE CRESCENZO, 1977, p.88, tradução minha)

No capítulo treze da narrativa principal, intitulado "Il basso", Bellavista discute, embasado na filosofia de Epicuro, sobre as preferências éticas dos napolitanos. Ademais, neste capítulo, discute com os outros personagens como o basso (baixo, em português), local da moradia de pessoas pobres do centro de Nápoles,

7 Perchè uno dei principali seguaci di Epicuro fu un certo Filodemo di Gadara, vissuto nel I secolo avanti Cristo. Filodemo si trasferì a Napoli, ad Ercolano per essere precisi, e qui fondò un'importantissima scuola epicurea sul modello del "Giardino di Atene". In questa scuola Filodemo insegnava al popolo napoletano la classificazione dei piaceri ed il disprezzo del potere. (DE CRESCENZO, 1977, p. 88)

8 2. A Napoli, negli edifici, vano aperto a livello della strada, per abitazione di povera gente (nel dialeto napol. vàscio)", ou seja, "2. Em Nápoles, os edifícios ficam abertos ao nível da rua, para habitação de pessoas pobres (no dialeto napolitano, vàscio - tradução minha). Trecho retirado do site Treccani, disponível em: <<//http://www.treccani.it/vocabolario/basso2//>>. Acesso em 19 de abril de 2019. 
pode ou não representar um aspecto positivo para a cidade. O personagem Vittorio acredita que, por lá haver tráfico de drogas, forte presença da máfia, prostituição e doenças como a cólera, não pode representar nada de positivo. Bellavista, todavia, acredita que não só representa um aspecto positivo, como é um lugar necessário e significativo. Seguindo a teoria da divisão dos prazeres epicuristas, os napolitanos que habitam esse local não estariam preocupados com os aspectos negativos apontados por Vittorio. Os moradores descartariam o prazer da riqueza, da fartura e da ordem já que lá existiria a união entre as pessoas e principalmente o prazer da amizade e das boas relações humanas.

Bellavista aponta que Vittorio, cidadão napolitano que foi morar em Milão, estaria em desacordo com a moral e ética napolitanas porque foi morar em uma cidade cuja população tem experiências e vivências diferentes daquelas propostas por Epicuro. Os milaneses, categorizados pelo professor como um povo que tende a liberdade, estariam mais ligados aos prazeres vãos, como o poder e a ordem.

Como mencionado anteriormente, o mestre napolitano acredita que as pessoas e os países podem ser divididos em:

(1) aqueles que tendem ao amor, entendido por ele como a necessidade e a capacidade de se conviver em conjunto com outras pessoas;

(2) à liberdade, entendida como a racionalidade: capacidade do homem de se livrar de sentimentos passionais e conseguir vivenciar o mundo de forma racional;

(3) ao ódio, entendido como incapacidade de se viver em conjunto. Desprezo pelas pessoas e falta de empatia

(4) e ao poder, entendido como uma tendência mesquinha e prazer de ordenar e comandar.

Os critérios usados por Bellavista para a divisão dessas categorias e a forma como ele pensa a ética e a moral dos napolitanos comparada à ética e à moral dos milaneses são baseados na dicotomia entre ordem x desordem e racional x irracional, o que conduz à noção de antinomia: contradição entre duas proposições filosóficas igualmente acreditáveis, coerentes ou lógicas, mas que levam a conclusões diametralmente opostas, demonstrando os limites cognitivos ou as contradições inerentes ao intelecto humano. Sendo assim, ao se refletir sobre a exposição de Bellavista, chega-se à antinomia apolíneo-dionisíaco, no sentido de se entender como ela colabora para se pensar essas dicotomias.

Essa antinomia, pensada por vários filósofos, entre eles Nietzsche, em Nascimento da tragédia (1871), foi aplicada pelo alemão para diferenciar os aspectos apolíneos, que dominariam as artes plásticas, e os aspectos dionisíacos, que dominariam a música, na cultura grega, por exemplo. Segundo Paul Strathern:

Essa brilhante e originalíssima análise da cultura grega coloca em contraste o claro elemento apolíneo de sobriedade clássica e as forças dionisíacas, mais sombrias e instintivas. Segundo Nietzsche, a grande arte da tragédia grega resultou da fusão desses dois elementos, sendo finalmente destruída pelo racionalismo superficial de Sócrates. Foi a primeira vez que se enfatizou o elemento sombrio da cultura grega, e sua caracterização por Nietzsche como fundamental provocou grande controvérsia. (STRATHERN, 1996, p.11)

Luciano De Crescenzo, na obra Ordem e desordem (1996), reflete sobre o apolíneo-dionisíaco lançando mão de diversos exemplos: na arte, no cinema, nos esportes e nos conceitos de bem e mal. O autor discute os termos antitéticos por toda a obra, mas principalmente no capítulo vinte e seis, intitulado "Notarella su Nietasche, Apollo e Dioniso" (Notazinha sobre Nietzsche, Apolo e Dioniso). Ele resume o mito de ambos os deuses, destacando suas características. Descreve Apolo como racional e Dioniso como passional, no trecho: 
Apolo-Dioniso: uma antinomia que faz pensar. O primeiro, sábio e distante, o segundo amante do encontro físico. Apolo, se mata, para não entrar em contato com as vítimas, usa o arco e as flechas. Dioniso, no entanto, as dilacera com as próprias mãos e, às vezes, não satisfeito, as devora. ${ }^{9}$ (DE CRESCENZO, p. 139, 1996, tradução minha).

As características do apolíneo podem ser entendidas, no contexto do romance aqui estudado, como os homens que tendem à liberdade: aqueles que se relacionam ordenada e racionalmente. As características do dionisíaco correspondem à categoria do amor: conectando os homens pela desordem, pela vivência dos prazeres e pela passionalidade. Logo, os napolitanos têm como cerne de sua ética e de sua moral as características do dionisíaco, enquanto os milaneses estariam no âmbito do apolíneo. O autor explicita ainda mais essas diferenças em I grandi miti greci (Os grandes mitos gregos):

$\mathrm{Na}$ vida, disse Nietzsche, há quem nasça dionisíaco e quem nasça apolíneo, e para entendê-lo basta distinguir quem comanda dentro de nós, se é o instinto ou se é a razão. Às vezes, basta ser um pouco mais reflexivo habitualmente para acabar entre os apolíneos, ou um pouco menos para ser categorizado entre os dionisíacos. Apenas os gênios, abençoados sejam, teriam ambos os impulsos, nós, no entanto, pessoas normais, somos ou um ou outro. ${ }^{10}$ (DE CRESCENZO,1999, p. 221, tradução minha)

O autor napolitano explora as qualidades racionais interligadas ao deus Apolo, destacando como as pessoas podem ser classificadas conforme esse meio de análise. É necessário explicitar, no entanto, que, para Nietzsche, as duas forças, a apolínea e a dionisíaca, em sua filosofia, são complementares e interdependentes. Segundo Carolina Cesarin Paes:

Não são elementos contrários, mas sim de unidade, complemento, no qual um é parte distinta do outro. $\mathrm{Na}$ obra $\mathrm{O}$ nascimento da Tragédia, Nietzsche representa essa união, pois, assim como a realidade, a tragédia é criada a partir da relação entre os contrários. A relação entre Apolo e Dioniso resulta na criação, pois a luta entre contrários cria uma nova síntese, uma nova percepção. Esses dois conceitos, embora antagônicos, fazem parte de uma mesma realidade, e, para Nietzsche, referem-se à completude e ao equilíbrio da própria natureza humana, e por isso não podem ser compreendidos de maneira isolada, pois caso isso aconteça corre-se o risco de mutilar o pensamento desse filósofo [...] (PAES, 2013, p. 145)

Dessa maneira, entendendo que o pensamento do filósofo alemão é complexo e demanda estudo, deve-se entender que De Crescenzo e outros autores que se valeram dessa forma de análise em suas obras, ficcionais ou não, adequaram-na aos seus próprios estilos e propósitos. De qualquer forma, a antinomia continuou a ser pensada para interpretar o mundo. Segundo Mirela Ribeiro Meira:

Até meados do século XX, o mundo podia ser percebido como ordem, a partir de certezas, da objetividade, da medição e da previsão. A civilização Apolínea, do fogo, da forja, do ferro, da máquina, teve seu auge no século XIX, com a Revolução Industrial. Dois séculos antes, a razão - ordem - havia sido eleita a forma mais importante de conhecer. A partir daí, realidades incertas, fronteiras móveis, jogos de

9 Apollo-Dioniso: un'antinomia che fa pensare. Il primo, saggio e distaccato, il secondo amante dello scontro fisico. Apollo, se uccide, proprio per non venire in contatto con le vittime, usa l'arco e le frecce. Dioniso, invece, le dilania con le proprie mani e volte, non soddisfatto, le divora. (DE CRESCENZO, 1996, p. 139)

10 Nella vita, dice Nietzsche, cè chi nasce dionisiaco e chi apollineo, e per capirlo basta individuare chi comanda dentro di noi, se l'istinto o la ragione. A volte è sufficiente essere un pochino più riflessivi del solito per finire tra gli apollinei, o un po' meno per essere schedati tra i dionisiaci. Solo i geni, beati loro, avrebbero ambedue gli impulsi; noi invece, gente normale, siamo l'uno o l'altro. (DE CRESCENZO, 1999, p. 221) 
possíveis exploram uma cartografia do imprevisível. Dioniso, o semideus ruidoso, das interrogações, (des) acomodações, desconcertos e rechaços às certezas, é observado, então, na Física Quântica, na Filosofia e nas vanguardas artísticas, demonstrando que ordem e desordem não se separam, antes tensionam relações complexas, misteriosas, enigmáticas. (MEIRA, 2013, p. 47)

Vê-se, segundo a autora, como o mundo, até o século XX, podia ser lido como apolíneo, relacionado à ordem e, depois, mais recentemente, ao dionisíaco, isto é, ao caótico, à desordem.

Continuando a discussão entre os personagens, é evidente como Bellavista e Vittorio têm posições diferentes. Vittorio tenta pensar o que há de apolíneo na região onde as pessoas pobres moram: a ordem relacionada à segurança, aos avanços tecnológicos e à saúde, embora não seja possível fazê-lo porque os napolitanos experenciam a vida dionisiacamente. Além disso, o filósofo ataca os argumentos do outro, de que no basso não existiria nada de positivo, ao mencionar a empresa em que seu adversário trabalha. Por estar situada em Milão, não há nela a "dimensão humana”, isto é, não há ligação de aspectos sentimentais de amor ou amizade entre os funcionários. Existe apenas a dimensão apolínea: a ordem e a racionalidade. Bellavista dialoga:

Veja, Vittorio, quando alguém diz: civilização, pensa rapidamente nas coisas mais importantes realizadas pelo homem e acaba confundindo civilização com progresso. A civilização verdadeira, no entanto, aquela da qual falo, é qualquer coisa de maior, é a presença do espírito do homem nas coisas. Você pega, por exemplo, a sua empresa de Milão, aquela na qual você trabalha. Bem, eu ainda não a conheço, é verdade, mas imagino que, como está em Milão, deve ser uma empresa organizadíssima: belíssimos escritórios, secretárias, centrais telefônicas e assim vai, e eis que eu te pergunto, Vittò: mas, segundo você, essa empresa é um fato do progresso ou da civilização? Tem alguma dimensão humana essa empresa na qual você se possa reconhecer? ${ }^{11}$ (DE CRESCENZO, 1977, p. 103, tradução minha)

O que está sendo discutido neste diálogo, destacado pelas palavras civilização e progresso, é a importância das evoluções materiais, tecnológicas, empresariais e econômicas de uma sociedade e se elas podem representar aspectos positivos ao se pensar em civilização ou progresso, já que, como explanado por Bellavista, as experiências humanas e o cultivo da boa relação entre as pessoas são mais importantes do que as evoluções materiais. No basso, pode não haver a ordem e a evolução que existem nas empresas de Milão, mas há a "dimensão humana". Isso faz com que esse lugar não seja só importante e necessário, mas também represente, por revelar as características dionisíacas mais pulsantes, uma das belas faces da cidade de Nápoles.

No capítulo vinte e cinco da narrativa principal, intitulado "La deliquenæa" (A delinquência), os personagens discutem os aspectos negativos relacionados aos furtos e à violência na cidade. Um deles usa a expressão "furto honesto" e Bellavista expõe como entende o furto de uma perspectiva epicurista-napolitana:

11 Vedi Vittò, quando uno dice civiltà pensa subito alle cose più importanti realizzate dall'uomo e finisce così con il confondere la civiltà con il progresso. La civiltà vera invece, quella che dico io, è qualcosa di più, è la presenza dello spirito dell'uomo nelle cose. Tu prendi per esempio la tua azienda di Milano, quella dove tu lavori, ora io adesso non la conosco, è vero, però immagino che siccome sta a Milano deve essere un'azienda organizzatissima: bellissimi uffici, segretarie, centralini telefonici e compagnia cantando, eppure Vittò io ti domando: ma secondo te, questa azienda è un fatto di progresso o di civiltà? Ha una dimensione umana questa azienda in cui tu ti puoi riconoscere? (DE CRESCENZO, 1977, p. 103) 
Digamos que o furto é um jogo competitivo, que, assim como todos os jogos, há suas regras precisas, pelas quais, se o ladrão que cometeu o furto, respeitou as regras, o roubado perde o direito do lamento e o crime se qualifica como "furto honesto".

"E quais seriam essas regras?"

"Primeiro: roubar apenas o necessário para a própria sobrevivência e de sua família."

"Então, se alguém tem uma família numerosa, é autorizado a roubar mais?"

"Epicuristicamente sim, por se tratar apenas do necessário. Segundo: roubar o supérfluo dos outros, sempre no caso de essas pessoas demonstraram não merecer essas coisas." ${ }^{2}$ (DE CRESCENZO, 1977, p. 180, tradução minha)

O filósofo continua explicando que se, epicuristicamente, um napolitano roubar uma câmera fotográfica de um estrangeiro americano ou suíço, pode ser considerado um "furto honesto" porque essas pessoas teriam vindo de países mais ricos, assim, os roubos menores praticados pelos napolitanos tenderiam a compensar a diferença econômica entre os países ricos, como os Estados Unidos e países pobres, como a Itália. Embora o diálogo seja narrado de forma que leve ao riso, Bellavista expõe sua reflexão baseada na interpretação da teoria epicurista: viver apenas com o necessário. O fato de um napolitano cometer um furto que supriria suas necessidades não tornaria o ato em uma ação amoral, nem antiética, embasada nessa visão epicurista-napolitana.

No capítulo sete da narrativa principal, intitulado "La teoria dell'amore e della libertă" (A teoria do amor e da liberdade), Bellavista esclarece ainda mais as diferenças entre os milaneses e os napolitanos ao afirmar que Vittorio foi influenciado pela conduta apolínea dos milaneses. Segundo Bellavista:

O doutor Palluoto se mudou para trabalhar em Milão há uns cinco ou seis anos e hoje é um importante diretor de uma importante sociedade de conselho da qual não lembro o nome, contudo quero dizer que, quando se mudou para Milão, Vittorio ficou, como dizer, "estragado", e aquelas mesmas coisas, que antes, em Nápoles, constituíam a sua vivência cotidiana, hoje resultam insuportáveis para ele. A verdade é que o nosso Vittorio perdeu aquele silenciador interno que abafava os ruídos do mundo do Amor e consequentemente mudou a escala de referências de seus valores: hoje Vittorio Palluoto vê na eficiência e na produtividade virtudes cardinais e acaba por supervalorizar os efeitos secundários e nocivos que essas alegadas virtudes comportam. ${ }^{13}$ (DE CRESCENZO, 1977, p. 50, tradução minha)

É explicito, neste trecho, como é depreciado o modo de viver contrário ao dos napolitanos e o desprezo pela valorização excessiva da eficiência e da produtividade, características de sociedades que

12 Diciamo che il furto è un gioco competitivo che come tutti i giochi ha delle regole precise, per cui, se il ladro nel commettere il furto ha rispettato queste regole, il derubato perde il diritto al lamento ed il reato si qualifica come "furto onesto".

"E quali sarebbero queste regole precise?"

"Primo: rubare solo lo stretto necessario alla propria sopravvivenza ed a quella della própria famiglia."

"Quindi se uno ha una famiglia numerosa è autorizzato a rubare di più?"

"Epicureisticamente sì, se si tratta del necessario. Secondo: rubare il superfluo degli altri, sempre nel caso però che questi altri abbiano dimostrato di non meritarselo." (DE CRESCENZO, 1977, p. 180)

13 II dottor Palluotto si trasferì per lavoro a Milano cinque o sei anni fa e oggi è un importante dirigente di un'importante società di consulenza di cui però non ricordo il nome comunque volevo dire che, da quando si è trasferito a Milano Vittorio si è, come dire, guastato, e quelle stesse cose, che prima a Napoli costituivano il suo vivere quotidiano, oggi gli risultano insopportabili. La verità è che il nostro Vittorio ha perso quel silenziatore incorporato che gli attutiva $i$ rumori caratteristici del mondo dell'Amore e di conseguenza ha cambiato la scala di riferimento dei suoi valori: oggi Vittorio Palluotto vede nell'efficienza e nella produttività le virtù cardinali e finisce col sottovalutare gli effetti secondari e deleteri che queste presunte virtù comportano. (DE CRESCENZO, 1977, p. 50) 
prezam pela organização e poder, ou seja, contrárias ao que Epicuro pregava: buscar apenas o necessário e evitar ao máximo os excessos, principalmente em relação ao poder.

Para o professor, Vittorio não é mais guiado pela via do amor porque, ao habitar na apolínea Milão, sua preferência pela ordem e pela valorização do dinheiro, destacadas no trecho: "vê na eficiência e na produtividade as virtudes cardinais", desumanizaram-no. Neste sentido, percebe-se que Bellavista acredita, por meio da perspectiva do dionisíaco e da ética e moral epicuristas, que se deve viver pelo amor: valorizar as relações humanas e os prazeres primários, e, consequentemente, rejeitar os prazeres proporcionados pela riqueza e pelo luxo dela decorrente.

Enquanto nos capítulos da narrativa principal os diálogos tocam as teorias do filósofo Epicuro, nas narrativas secundárias são demonstrados como esses princípios seriam vivenciados no cotidiano dos napolitanos.

No capítulo vinte e quatro, intitulado "Geraldinho, o kamikąe", a moral e a ética napolitanas ficam explícitas pelo modo como o personagem Geraldinho age depois de perder o emprego que havia herdado de sua família. A anedota, que, como já afirmado, define uma narrativa curta e divertida, é narrada por Salvatore para o De Crescenzo ficcional, no romance chamado de "engenheiro".

Geraldinho era luveiro, profissão que herdou de sua família. Contudo, as luvas saíram de moda e ele teve de arrumar outra ocupação. Como era casado e tinha filhos, teve de arrumar um modo de ganhar dinheiro rapidamente: passou a roubar grades de bronze dos vagões de trem. Depois de um tempo, pararam de colocar grades de bronze nos trens e Geraldinho teve, novamente, que arrumar outra ocupação: começou a forjar acidentes de carro para receber o dinheiro de seguradoras, ficando conhecido por elas e por todos no bairro pelos seus feitos.

São exploradas, na anedota, as ações morais e éticas gradativas do personagem. Inicialmente furta objetos para vendê-los. Em seguida, planeja e executa, detalhadamente, os acidentes dos carros para obter o dinheiro das seguradoras, correndo perigo de se machucar ao executá-los.

O personagem age de maneira epicurista-napolitana ao decidir roubar e depois enganar grandes corporações, como as de seguro, para conseguir o dinheiro que suprisse suas necessidades. Se, para Bellavista, o fato de os napolitanos roubarem estrangeiros de países ricos não implica em uma ação antiética e amoral, Geraldinho também não age antiética e amoralmente porque não rouba ou engana pessoas pobres, mas empresas supostamente com grande capital.

Além disso, a ironia do narrador expõe a aprovação das atitudes de Geraldinho. No trecho: “Ainda pode correr o risco de ser abordado por piratas das estradas, gente desonesta sem consciência civil, que, para evitar gastar dinheiro, são capazes de qualquer coisa.” (DE CRESCENZO, 1977, p. 173), é possível observar que os piratas, que estariam agindo moral e eticamente semelhante a Geraldinho, são adjetivados e descritos como "gente desonesta" e "sem consciência civil". No entanto, Geraldinho, que furtou objetos, planeja e executa acidentes para obter dinheiro de seguradoras, não é adjetivado como ladrão ou pessoa desonesta. Pelo contrário, os adjetivos que são usados para descrevê-lo são: artista, boa pessoa, coitadinho e perito. A ironia desses adjetivos evidencia o bom humor do narrador da anedota, assim como demonstra a apreciação pelo personagem e pela forma como ele age.

A narração também exalta a esperteza e perspicácia de Geraldinho. Os trechos:

(1) "decidiu empreender numa carreira, digamos assim, mais moderna, e se meteu no ramo dos seguros” (DE CRESCENZO, 1977, p. 173);

(2) "Geraldinho tem as manhas: calcula, em uma fração de segundos, a velocidade do carro, a prontidão de reflexos do motorista, o tipo de carro e o nível econômico do proprietário” (DE 
CRESCENZO, 1977, p. 173) e

(3) “Hoje, Geraldinho, graças a Deus, fez para si um nome e se colocou a trabalhar no varejo." (DE CRESCENZO, 1977, p. 173)

salientam o cuidado do narrador ao utilizar a ironia e o eufemismo ao atenuar as ações do personagem e apresentar Geraldinho ao seu interlocutor, usando o léxico do contexto de trabalho "carreira" e "ramo", como alguém que está inserido em um emprego formal e não como alguém que está realizando ações que infringem as leis. Ainda, o segundo trecho evidencia a esperteza do personagem, exaltando-o pela maneira que narra as qualidades que ele tem em calcular e executar suas ações. $O$ último trecho, novamente, valora as ações do personagem, como pode ser percebido em: "fez um nome para si" ou pelo uso do léxico do contexto de trabalho e empresarial "varejo", ao se referir a como ele conseguiu manter e depois expandir sua forma de lucro.

Como afirmado anteriormente, a comicidade apresenta-se permeada por todo o romance, principalmente nas anedotas. Pela via do humor é que são exploradas a cultura, a ética e a moral napolitanas. No diálogo da anedota sobre Geraldinho, percebe-se como a esperteza e o comportamento do personagem são exaltados. No trecho final: "deveriam dar a ele, como se diz...honoris causa”, é evidente o humor, mas também o não julgamento, ou até mesmo a aprovação de como Geraldinho age.

\section{Considerações finais}

Foram verificadas, neste artigo, as influências filosóficas nas considerações do personagem ficcional Gennaro Bellavista, do romance Cosi parlò Bellavista, citadas durante os diálogos com seus colegas, principalmente com o contestador Vittorio Palluoto. Como visto, os ensinamentos de Epicuro são a base das teorias do professor quando este discute a ética e a moral napolitanas. O filósofo grego acreditava que os prazeres poderiam ser divididos em categorias: os prazeres naturais e necessários; os prazeres naturais e não necessários, e os prazeres não naturais e não necessários que deviam ser desprezados, como o poder e o luxo.

Bellavista acredita que os napolitanos têm a ética e a moral embasadas nos preceitos de Epicuro por preferirem vivenciar os prazeres primários e por desprezarem a ordem e o desejo de poder. Além disso, o professor cria suas próprias categorias que distinguem quem tende ao amor, liberdade poder e ódio. Ademais, foi refletido também como a antinomia apolíneo-dionisíaco ajuda a compreender as diferenças entre os passionais e afetuosos napolitanos versus os racionais e impassíveis milaneses. Nesse sentido, a anedota "Geraldinho, o kamikaze”, analisada aqui, evidencia não só o aspecto da esperteza do personagem Geraldinho, mas a conduta epicurista-napolitana e a tendência dionisíaca desse povo.

Como discutido logo no início, por meio da Literatura e da Filosofia pode-se refletir sobre a conduta humana. De Crescenzo o faz, inserindo nos diálogos ficcionais entre amigos, a cultura filosófica somada à cultura popular de Nápoles. A obra é feliz ao atingir o leitor com o característico bom humor napolitano, fazendo-o conhecer e pensar sobre as antigas perspectivas filosóficas que ainda influenciam o pensamento crítico e a ficção. 


\section{ANEXO}

\section{Geraldinho, o kamikaze}

"Engenheiro, se você for em dez minutos, te apresento Geraldinho, o kamikaze?"

"Geraldinho quem?

"Geraldinho, o kamikaze”" repete Salvador. "Geraldinho é um amigo meu e de Saverio, também um grande personagem napolitano, conhecido pelas maiores companhias de seguro italianas."

"E o que faz esse Geraldinho?"

"Joga-se em baixo dos carros para ganhar dinheiro das seguradoras."

"Belo amigo você tem, Salvador!"

“É não, caríssimo engenheiro, vamos devagar". Rebate Salvador com um tom ressentido. "Deve-se ter estima por ele. E depois de pensarmos bem, vê-se que é uma boa pessoa: não sei quantas costelas quebrou fazendo essas artimanhas".

"Eu sei apenas que, por culpa desses Geraldinhos, devo pagar o dobro do preço da mensalidade para a seguradora do meu carro. Isso parece certo para você?"

"Agora devo contar a história de Geraldinho. Geraldinho, como profissional, era luveiro, assim como o pai, o avô, o bisavô etc etc. Só que, de repente, a moda mudou e as luvas não serviam para mais nada, a não ser para os assassinos que não queiram deixar impressão digital. Assim, o pobre Geraldinho, que era casado há dezoito anos e tinha alguns filhos, foi obrigado a ter de se virar. Por um curto período de tempo, especializou-se em roubar as grades de bronze que ficavam nos gabinetes dos trens. Ele andava de trem, arrancava a grade de bronze, que estava presa no pavimento, jogava-a para fora, no mato, e depois voltava com calma para buscar. Mas, de novo, a moda estava contra Geraldinho. As ferrovias do Estado decidiram trocar a maneira de fazer os gabinetes dos trens e o nosso pobre Geraldinho teve que mudar de profissão. Agora, decidiu empreender numa carreira, digamos assim, mais moderna, e se meteu no ramo dos seguros, que, depois, como diz a palavra, assegurou-lhe certa tranquilidade."

"Com licença, os seguros são dos incidentes simulados?"

"Mas que simulados, engenheiro, ele realmente se joga embaixo dos carros."

"E não se machuca?"

"Não, porque é um artista! Geraldinho tem as manhas: calcula, em uma fração de segundos, a velocidade do carro, a prontidão de reflexos do motorista, o tipo de carro e o nível econômico do proprietário. Resumindo, vocês devem entender que, se ele faz um pequeno erro de cálculo, Geraldinho pode realmente se machucar. Ainda pode correr o risco de ser abordado por piratas das estradas, gente desonesta sem consciência civil, que, para evitar gastar dinheiro, são capazes de qualquer coisa."

"E, então, coitadinho, de vez em quando, se machuca mesmo."

"Sim, de vez em quando. Leva um golpe hoje, cai amanhã. Geraldinho já está ficando velho. Mas, em compensação, conseguiu arranjar-se com dinheiro. Pensem que ele mesmo me disse que, há pouco tempo, os Seguros Italianos se reuniram em um congresso por culpa dele e parece que lhe ofereceram uma compensação de plano mensal, desde que não se jogasse mais embaixo dos carros. Resumindo: uma espécie de pensão."

"Menos mal, assim não arrisca mais a vida"

"Mas agora não compensa mais para Geraldinho o emprego fixo. Tinham que lhe oferecer esse cargo 
antes! Hoje, Geraldinho, graças a Deus, fez para si um nome e se colocou a trabalhar no varejo.”

"Como assim, varejo?"

"Geraldinho não se limita mais apenas aos incidentes pessoais. Não, ele praticamente conquistou outras fraturas. Que eu saiba...qualquer um do bairro que se machuque, por exemplo: alguém cai da escada e quebra uma perna, pois bem, invés de ir direto para o hospital, avisa primeiramente Geraldinho, que combina imediatamente um incidente falso com um carro de qualquer amigo segurado, e depois o leva ao hospital."

"O que você disse?"

"E como vocês podem imaginar, ao fraturado a coisa convém muitíssimo, também porque além de uma compensação apropriada, recebe imediatamente de Geraldinho uma assistência legal e médica de primeira qualidade: Geraldinho é um perito da medicina legal, basta-lhe apenas ouvir alguns gemidos do paciente para identificar o tipo de fratura, os dias de repouso e a soma de ressarcimento pelo dano. Resumindo, engenheiro, acho que Geraldinho poderia trabalhar no hospital traumatológico de Capodimonte. Deveriam dar a ele, como se diz... honoris causa.

(DE CRESCENZO, L. Gennarino ‘o kamikazze. In. Così parlò Bellavista: Napoli, amore e libertà. Milano: Mondadori, 1977. p. 171-173, tradução minha)

\section{REFERÊNCIAS}

ABBAGNANO, N. Dicionário de Filosofia. São Paulo: Martins Fontes, 2007.

DE CRESCENZO, L. Cosi parlò Bellavista: Napoli, amore e libertà. Milano: Mondadori, 1977.

. Ordine e disordine. Milano: Mondadori, 1996.

. I grandi miti greci: gli dei, gli eroi, gli amori, le guerre. Milano: Mondadori, 1999.

. História da filosofia grega: os pré-socráticos. Tradução: Mario Fondelli. Rio de Janeiro: Rocco digital, 2012a.

. História da filosofia grega: de Sócrates aos neoplatônicos. Tradução: Mario Fondelli. Rio de Janeiro: Rocco digital, 2012b.

EPICURO. Antologia de textos de Epicuro. In: Os pensadores: Epicuro, Lucrécio, Cícero, Sêneca, Marco Aurélio. Traduções e notas de Agostinho da Silva ... [et al.]; estudos introdutórios de E. Joyau e G. Ribbeck. - 3. ed. - São Paulo: Abril Cultural, 1985.

. Carta sobre a felicidade: (a Meneceu). Tradução: Álvaro Lorencini e Enzo Del Carratore. São Paulo: Editora Unesp, 2002.

KIRKLAND, R. The book of Mozi (Mo-Tzu). Disponível em: //<< https://faculty.franklin.uga.edu/sites/faculty.franklin.uga.edu.kirkland/files/MOTZU.pdf//>>. Acesso em 13 de março de 2019.

MEIRA. R. M. Ordem e desordem: criação e metamorfoses ético-estéticas na formação docente. Revista Paralelo 31 issn: 2358-2529, edição 01 - dezembro de 2013. Disponível em: <<//https://wp.ufpel.edu.br/paralelo31/files/2015/03/05_artigo04_mirela.pdf//>>. Acesso em 26 de abril de 2019.

NIETZSCHE, F. Assim falava Zaratustra: um livro para todos e para ninguém. Tradução: Paulo Cesar 
de Souza. São Paulo: Companhia das Letras, 2011.

PAES, C. C. O apolíneo e o dionisíaco no pensamento de Nietzsche. Diálogos literários. ISBN: $978-$ 85-88753-26-6. Disponível em: <<//https://dialogosliterarios.files.wordpress.com/2013/12/40. pdf//>>. Acesso em 19 de abril de 2019.

SOUSA, P. E. Q. Literatura e Filosofia: Uma leitura dos romances de Gonçalo M. Tavares. Dissertação para a obtenção do grau de mestre em Literatura. Faro, 2007. Disponível em: //<< https://sapientia.ualg.pt/handle/10400.1/262//>>. Acesso em 22 de outubro de 2018.

STRATHERN, P. Nietzsche em 90 minutos. Tradução: Maria Helena Geordane. Rio de Janeiro: Zahar, 1997.

Artigo recebido em: 22 de março de 2019

Artigo aceito em: 01 de julho de 2019 